\title{
Comparison of laparoscopic and mini incision open donor nephrectomy: single blind, randomised controlled clinical trial
}

Niels F M Kok, May Y Lind, Birgitta M E Hansson, Desiree Pilzecker, Ingrid R A M Mertens zur Borg, Ben C Knipscheer, Eric J Hazebroek, Ine M Dooper, Willem Weimar, Wim C J Hop, Eddy M M Adang, Gert Jan van der Wilt, Hendrik J Bonjer, Jordanus A van der Vliet, Jan N M IJzermans

\begin{abstract}
Objectives To determine the best approach for live donor nephrectomy to minimise discomfort to the donor and to provide good graft function.

Design Single blind, randomised controlled trial.

Setting Two university medical centres, the Netherlands.

Participants 100 living kidney donors.

Interventions Participants were randomly assigned to either laparoscopic donor nephrectomy or to mini incision muscle splitting open donor nephrectomy.

Main outcome measures The primary outcome was physical fatigue using the multidimensional fatigue inventory 20 (MFI-20). Secondary outcomes were physical function using the SF-36, hospital stay after surgery, pain, operating times, recipient graft function, and graft survival.

Results Conversions did not occur. Compared with mini incision open donor nephrectomy, laparoscopic donor nephrectomy resulted in longer skin to skin time (median $221 \mathrm{v}$ 164 minutes, $\mathrm{P}<0.001$ ), longer warm ischaemia time (6 63 minutes, $\mathrm{P}<0.001$ ), less blood loss (100 $240 \mathrm{ml}, \mathrm{P}<0.001)$, and a similar number of complications (intraoperatively $12 \% v$ $6 \%, \mathrm{P}=0.49$, postoperatively both $6 \%$ ). After laparoscopic nephrectomy, donors required less morphine (16 v $25 \mathrm{mg}$, $\mathrm{P}=0.005)$ and shorter hospital stay $(3 v 4$ days, $\mathrm{P}=0.003)$. During one year's follow-up mean physical fatigue was less (difference $-1.3,95 \%$ confidence interval -2.4 to -0.1 ) and physical function was better (difference 6.2, 2.0 to 10.3) after laparoscopic nephrectomy. Function of the graft and graft survival rate of the recipient at one year censored for death did not differ (100\% after laparoscopic nephrectomy and 98\% after open nephrectomy).

Conclusions Laparoscopic donor nephrectomy results in a better quality of life compared with mini incision open donor nephrectomy but equal safety and graft function.
\end{abstract}

\section{Introduction}

Kidney transplantation is the best option for patients with end stage renal disease. As the number of patients requiring kidney replacement therapy is increasing, the recruitment of more kidney donors is important. Donation of a kidney from a live donor is the most realistic option to expand organ donation. ${ }^{1}$ From an ethical point of view, living donation becomes more acceptable if harm to the donor and the graft is limited. Therefore optimising the management of the living donor including screening, surgery, and anaesthesia is important.
Traditionally the kidney was removed through a flank incision, often including rib resection to allow sufficient access. This resulted in major postoperative pain, incisional hernias, and chronic neuralgia. Using small incisions has improved the comfort of the donor. In less than a decade, laparoscopic surgery has been adopted by most centres. Laparoscopic donor nephrectomy was first carried out in $1995 .^{2}$ Concurrently the technique of open donor nephrectomy has been refined to a muscle sparing mini incision without resection of the ribs, which has improved convalescence of the donors. ${ }^{3-5}$ To date the best surgical technique within the multidisciplinary management of living donors is not defined.

We carried out a prospective randomised trial to compare laparoscopic donor nephrectomy with mini incision open donor nephrectomy for fatigue and quality of life of the donors and for clinical outcomes.

\section{Participants and methods}

We recruited to our study living kidney donors at the university medical centres in Rotterdam and Nijmegen. Eligible donors were informed about the surgical approaches and invited to participate in the study. Screening of donors included preoperative examination by a nephrologist, renal ultrasonography, and magnetic resonance angiography or computed tomographyangiography to evaluate the arterial and venous anatomy of the kidneys. If both kidneys were suitable for transplantation the right kidney was preferred. ${ }^{6}$ Exclusion criteria were bilateral abnormalities of the renal arteries (origin stenosis), previous operations of the kidney or adrenal gland, radiological abnormalities necessitating a modified approach (for example, solid tumours requiring frozen sections), and the inability to read Dutch. Patients were not excluded because of age, multiple arteries, obesity, or previous abdominal surgery other than adrenal or renal surgery. The day before surgery the surgeon confirmed that the patient had given informed consent.

\section{Randomisation}

The surgeon telephoned the study coordinator after informed consent had been confirmed, who opened the next numbered sealed opaque envelope provided by the trial statistician. Randomisation was carried out according to a computer generated list using a hidden block size of four. Stratification was not 
by centre. Donors were randomised less than 12 hours before surgery. All healthcare professionals except the surgical team were unaware of the allocated procedure. At the end of the operation the abdomen of all donors was covered with a standard pattern of dressings stained with one or two drops of blood to simulate real wound dressings. In case of an emergency, a sealed envelope detailing the procedure was left in the patient's notes.

\begin{abstract}
Anaesthesia and analgesia
Donors were prehydrated with intravenous crystalloids. Antithrombotic stockings were used routinely. After endotracheal intubation, anaesthesia was carried out according to a strict protocol for drugs, ventilation, and fluid regimens. One hour after the start of surgery the donors received $20 \mathrm{mg}$ mannitol. Except for one donor who required endocarditis prophylaxis, no antibiotics were given. At the end of surgery donors received patient controlled analgesia using intravenous morphine. They were also offered two $500 \mathrm{mg}$ paracetamol tablets four times daily until discharge. The device for patient controlled analgesia was removed when morphine had not been required for at least six hours.
\end{abstract}

\section{Surgical procedures}

The surgical procedures were carried out by one of four surgeons skilled in both techniques. The trial coordinator in each centre attended the operations to document blood loss, operation time, use of instruments, and complications. Complications were defined as events necessitating intraoperative or postoperative interventions or that prolonged hospital stay.

Both techniques were carried out as described previously, ${ }^{5}$ with the donor in a lateral decubitus position. Briefly, during laparoscopic nephrectomy the camera and three or four additional trocars were introduced under vision. After dissection of the kidney, ureter, and vascular structures, an endobag (Endocatch; US Surgical, Norwalk, CT, USA) was introduced. The renal artery and vein were divided with linear stapling devices (Endo GIA; US Surgical), and the kidney was extracted through a pfannenstiel incision. The skin wounds were sutured intracutaneously

To enable mini incision open nephrectomy a horizontal skin incision 10-12 cm long was made anterior to the 11th rib. The fascia and muscles of the abdominal wall were split using a mechanical retractor (Omnitract surgical, St Paul, USA). Gerota's fascia was opened on the lateral side of the kidney. After dissection of the kidney the surgeon clamped, cut, and ligated the ureter, renal artery, and vein. The kidney was extracted. The fascias of the abdominal muscles were closed, the subcutaneous fascia was approximated, and the skin was sutured intracutaneously.

\section{Postoperative data and quality of life}

The donor determined timing of discharge on the basis of tolerance to a normal diet and ability to use stairs. We calculated postoperative hospital stay with and without correction for time spent in hospital as a result of non-medical reasons (lack of care at home). Donors were seen at the outpatient clinic at three weeks, three months, and one year postoperatively. They were asked to complete forms related to pain, nausea, body image, fatigue, and quality of life. Preoperatively and at days 1, 3, 7, and 14 the donors scored pain and nausea on a visual analogue scale from 0 (none) to 10 (severe).

Body image was assessed at one year postoperatively using the body image questionnaire, ${ }^{7}$ which consists of two scales: the body image scale, which assesses attitudes to bodily appearance and consists of five questions (score 5-20), and the cosmetic scale, which assesses degree of satisfaction with the appearance of the scar and consists of three questions (score 3-24). Higher scores on both scales indicate greater satisfaction.

To assess whether laparoscopic nephrectomy and open nephrectomy differentially affected health related quality of life and fatigue, we administered the SF-36 and the multidimensional fatigue inventory 20 (MFI-20) preoperatively and at 1,3,6, and 12 months postoperatively. The SF-36 includes one multi-item scale measuring each of eight health concepts: physical function, role limitations due to physical health problems, bodily pain, general health, vitality, social functioning, role limitations due to emotional problems, and mental health. ${ }^{8}$ Scores per dimension of the SF-36 ranged from 0 to 100 , with higher scores indicating better quality of life. We considered a five point difference between laparoscopic nephrectomy and open nephrectomy on a dimension as minimally clinically relevant. ${ }^{8}$

We determined levels of fatigue using the MFI- $20,{ }^{9}$ which consists of 20 items divided into five scales: general fatigue, physical fatigue, reduced activity, reduced motivation, and mental fatigue. Scores per item ranged from 1 to 5: total score per scale ranged from 4 (no fatigue) to 20 (exhausted).

\section{Recipients}

Recipients were admitted to a surgical ward separated from that of the donor to minimise influence on the donor's recovery. Renal transplantation was carried out using the standard technique of preperitoneal placement in the iliac fossa. The immunosuppressive regimen included mycophenolate mofetil, tacrolimus, and prednisone. During the first year postoperatively we recorded survival rates of recipients and grafts, acute rejection rates (histologically proved), venous thrombosis, and ureteral complications as defined as the need for a percutaneous nephrostomy, ureter reconstructions, and renal function.

\section{Statistical analysis}

Fatigue and quality of life are closely related. However, fatigue as an outcome of the intervention might be more suitable for indicating the effect of a surgical approach than the quality of life test. The quality of life test may be influenced by other factors, such as satisfaction after donor nephrectomy. The primary outcome was therefore physical fatigue on the MFI-20 and the secondary outcome was physical function on the SF-36. Other secondary end points were postoperative hospital stay, pain, operating times, recipient graft function, and graft survival. Power calculations were based on physical fatigue. Fifty donors had to be included in each arm to establish a moderate significant difference of 0.6 standard deviations in physical fatigue with a power of $80 \%$ and an $\alpha$ of 0.05 . We used the $\chi^{2}$ test to compare categorical variables and the Mann-Whitney U test to compare continuous variables. Repeated measurement of analysis of covariance was used to compare repeated continuous variables. We adjusted repeated measures for baseline values, donor's sex, and age. Analyses were carried out using SPSS version 11.0. We analysed data according to the intention to treat principle. $P$ values less than 0.05 (two sided) were considered statistically significant.

\section{Results}

From November 2001 until February 2004 we recruited 105 of 163 living kidney donors to the study (fig 1). Two of the 163 donors were excluded because they were participating in a living donor kidney exchange programme. ${ }^{10}$ After randomisation one operation was cancelled and four were postponed because of 


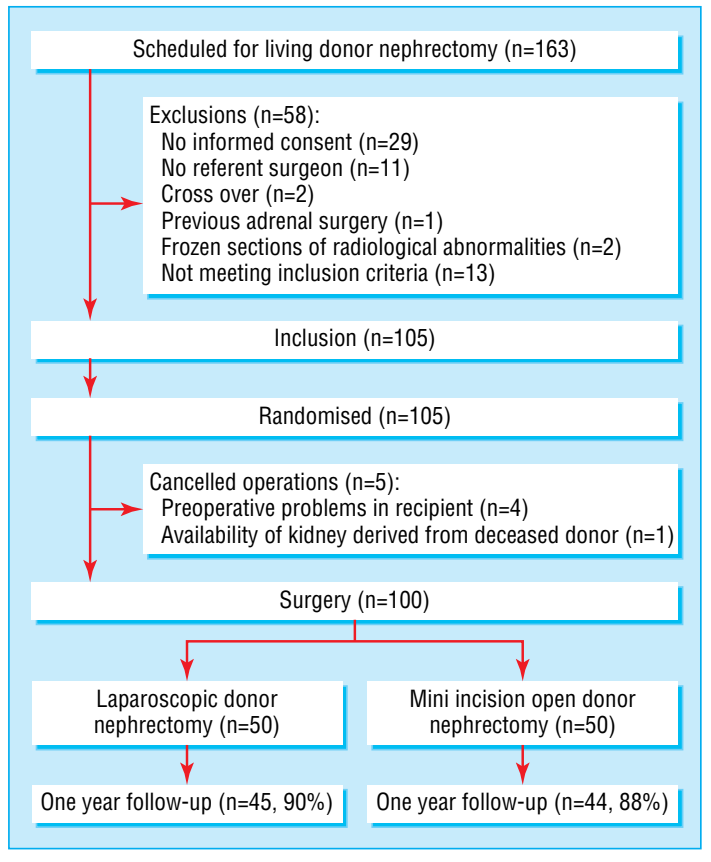

Fig 1 Flow of patients

clinical or radiological findings on the night before surgery. The Rotterdam centre carried out 34 laparoscopic donor nephrectomies and 38 mini incision open donor nephrectomies. The Nijmegen centre carried out 16 laparoscopic nephrectomies and 12 open nephrectomies. The number of participants was smaller in Nijmegen because recruitment was delayed while awaiting ethical approval. Table 1 shows the baseline characteristics of the donors and recipients.

\section{Surgery}

The procedures were all carried out as planned without conversion to open or formal lumbotomy (table 2). In the laparoscopic group skin to skin time and warm ischaemia time were significantly longer and blood loss was less. Intraoperative complications occurred in six patients $(12 \%)$ during laparoscopic nephrectomy, which were bleeding in three (total blood loss 400$860 \mathrm{ml}$ ), a serosal lesion of the colon, a bladder lesion, and a small capsular tear of the spleen. The lesions were recognised immediately and treated without conversion. Re-interventions were not indicated. The three $(6 \%)$ complications during open nephrectomy involved bleeding (total blood loss 1000-1800 ml), which was controlled during surgery.

\section{Postoperative outcomes}

Laparoscopic nephrectomy resulted in faster recovery as reflected by earlier resumption of a normal diet, less need for intravenous morphine, and earlier discharge (table 2). During the first two weeks donors in the laparoscopic group experienced significantly less pain. Postoperative complications after laparoscopic nephrectomy were wound infections at the extraction site in two donors, which were treated with oral antibiotics, and a blood transfusion. Complications after open nephrectomy were a urinary tract infection, a minor pulmonary infiltrate (both not requiring antibiotics), and an infected retroperitoneal haematoma, for which the patient required readmission for intravenous antibiotics. Other complications, such as incisional hernias, did not occur. Donors in both groups had similar serum creatinine levels. Scores on the body image scale did not differ significantly between the groups.
Table 1 Baseline characteristics of living kidney donors and recipients according to nephrectomy technique. Values are numbers (percentages) unless stated otherwise

\begin{tabular}{|c|c|c|}
\hline Variable & $\begin{array}{l}\text { Laparoscopic donor } \\
\text { nephrectomy } \\
(\mathrm{n}=50)\end{array}$ & $\begin{array}{c}\text { Mini incision open } \\
\text { donor nephrectomy } \\
(\mathrm{n}=50)\end{array}$ \\
\hline \multicolumn{3}{|l|}{ Donor } \\
\hline Male & $29(58)$ & $24(48)$ \\
\hline Female & $21(42)$ & $26(52)$ \\
\hline Median (range) age (years) & $49(20-77)$ & $48.5(21-75)$ \\
\hline \multicolumn{3}{|l|}{ Kidney removed: } \\
\hline Left & $30(60)$ & $31(62)$ \\
\hline Right & $20(40)$ & $19(38)$ \\
\hline \multicolumn{3}{|l|}{ Preoperative physical status: } \\
\hline I (healthy) & $38(76.0)$ & $34(68)$ \\
\hline II & $12(24.0)$ & $15(30)$ \\
\hline III & & $1(2)$ \\
\hline Median (range) body mass index & $25.9(16.5-36.6)$ & $26.0(17.7-33.2)$ \\
\hline \multicolumn{3}{|l|}{ Renal arteries: } \\
\hline 1 & $37(74)$ & $40(80)$ \\
\hline$\geq 2$ & $13(26)$ & $10(20)$ \\
\hline \multicolumn{3}{|l|}{ Renal veins: } \\
\hline 1 & $42(84)$ & $46(92)$ \\
\hline$\geq 2$ & $8(16)$ & $4(8)$ \\
\hline $\begin{array}{l}\text { Median (range) preoperative serum creatinine } \\
\text { level }(\mu \mathrm{mol} / \mathrm{l})\end{array}$ & $76(49-105)$ & 79 (54-99) \\
\hline Median (range) physical function $\dagger$ & $95(35-100)$ & $100(45-100)$ \\
\hline Median (range) physical fatiguef & $4(4-10)$ & $4.0(4-20)$ \\
\hline \multicolumn{3}{|l|}{ Recipient } \\
\hline Male & $32(64)$ & $23(46)$ \\
\hline Female & $18(36)$ & $27(54)$ \\
\hline Median (range) age (years) & $48(13-68)$ & $44(11-72)$ \\
\hline \multicolumn{3}{|l|}{ Relation between donor and recipient: } \\
\hline Related & $39(78)$ & $35(70)$ \\
\hline Unrelated & $11(22)$ & $15(30)$ \\
\hline $\begin{array}{l}\text { Median (range) preoperative serum creatinine } \\
\text { level }(\mu \mathrm{mol} / \mathrm{l})\end{array}$ & 799 (299-1793) & $783(300-1777)$ \\
\hline
\end{tabular}

\section{Recipients}

One recipient (laparoscopic nephrectomy) died on the first postoperative day due to myocardial infarction. Two others (one in each group) died in the first year due to progressive infections related to an immunocompromised status. One recipient's graft (open nephrectomy) did not survive due to vascular rejection (table 2). She currently undergoes haemodialysis. Renal vein thrombosis did not occur in either group. Three recipients had ureteral complications after open nephrectomy, including ureteral stenosis and leaking, leading to ureteral reconstructions. Serum creatinine levels in recipients of kidneys from donors in both groups decreased in parallel without any significant differences over time.

\section{Quality of life and fatigue}

Response ranged from $97 \%$ at one month to $89 \%$ at 12 months, with an equal distribution at all times between laparoscopic and open nephrectomy. At baseline donors in both groups had excellent health status. ${ }^{8}$ Scores on the domains role physical and bodily pain were comparable at all time points (table 3 ). All other dimensions differed over time in favour of laparoscopic nephrectomy. Figure 2 shows scores for physical function over time in both groups. Patients in the laparoscopic group had higher mean scores for physical function during follow-up, indicating better quality of life (difference 6.2 points, $95 \%$ confidence interval 2.0 to $10.3, \mathrm{P}=0.004)$. Similar patterns were found for the other dimensions (see bmj.com). 
Table 2 Surgical outcomes of living kidney donors and postoperative outcomes of donors and recipients. Values are numbers (percentages) unless stated otherwise

\begin{tabular}{|c|c|c|c|}
\hline Variable & $\begin{array}{l}\text { Laparoscopic donor } \\
\text { nephrectomy }(n=50)\end{array}$ & $\begin{array}{c}\text { Mini incision open } \\
\text { donor nephrectomy } \\
\quad(n=50)\end{array}$ & $P$ value \\
\hline \multicolumn{4}{|l|}{ Donor } \\
\hline $\begin{array}{l}\text { Conversion to open donor } \\
\text { nephrectomy }\end{array}$ & 0 & - & - \\
\hline \multicolumn{4}{|l|}{ Median (range) time (min): } \\
\hline Kidney removal & $181(107-307)$ & $118(61-201)$ & $<0.001$ \\
\hline Skin to skin & 221 (135-354) & 164 (92-298) & $<0.001$ \\
\hline In operating theatre & $289.5(180-420)$ & $226(157-365)$ & $<0.001$ \\
\hline $\begin{array}{l}\text { Median (range) warm } \\
\text { ischaemia time (min) }\end{array}$ & $6(2-14)$ & $3(1-6)$ & $<0.001$ \\
\hline Blood loss (ml) & $100(10-860)$ & $240(20-1800)$ & $<0.001$ \\
\hline \multicolumn{4}{|l|}{ Complications: } \\
\hline Intraoperative & $6(12)$ & $3(6)$ & 0.23 \\
\hline Postoperative & $3(6)$ & $3(6)$ & 1.00 \\
\hline $\begin{array}{l}\text { Median (range) resumption } \\
\text { of normal diet }(\mathrm{h})\end{array}$ & $19.5(3-48)$ & $24(16-72)$ & 0.01 \\
\hline $\begin{array}{l}\text { Median (range) morphine } \\
\text { requirement (mg) }\end{array}$ & $16(0-93)$ & $25(1-107)$ & 0.005 \\
\hline \multicolumn{4}{|l|}{$\begin{array}{l}\text { Median (range) length of } \\
\text { hospital stay (days): }\end{array}$} \\
\hline Unadjusted & $3(1-6)$ & $4(2-8)$ & 0.003 \\
\hline Adjusted $^{\star}$ & $3(1-6)$ & $3(2-8)$ & 0.002 \\
\hline \multicolumn{4}{|l|}{$\begin{array}{l}\text { Median (range) serum } \\
\text { creatinine level }(\mu \mathrm{mol} / \mathrm{l}) \text { : }\end{array}$} \\
\hline Day 1 & $112(75-158)$ & $112.5(68-183)$ & 0.81 \\
\hline Day 2 & $118(76-167)$ & 117.5 (74-222) & 0.99 \\
\hline Month 3 & $107(76-157)$ & 117 (79-191) & 0.31 \\
\hline Year 1 & 107 (72-153) & 114 (75-169) & 0.17 \\
\hline \multicolumn{4}{|l|}{ Median (range) nausea†: } \\
\hline Day 1 & $0(0-9.2)$ & $0(0-7.7)$ & 0.52 \\
\hline Day 3 & $0(0-4.6)$ & $0(0-5.2)$ & 0.24 \\
\hline Day 7 & $0(0-3.2)$ & $0(0-8.0)$ & 0.31 \\
\hline Day 14 & $0(0-2.2)$ & $0(0-8.0)$ & 0.14 \\
\hline \multicolumn{4}{|l|}{ Median (range) pain†: } \\
\hline Day 1 & $2.7(0-6.2)$ & $3.5(0-7.7)$ & 0.04 \\
\hline Day 3 & $1.4(0-6.6)$ & $1.8(0-7.8)$ & 0.12 \\
\hline Day 7 & $0.4(0-6.1)$ & $1.7(0-8.0)$ & 0.03 \\
\hline Day 14 & $0(0-4.8)$ & $0.4(0-8.0)$ & 0.008 \\
\hline \multicolumn{4}{|l|}{$\begin{array}{l}\text { Median (range) body image } \\
\text { questionnaire: }\end{array}$} \\
\hline Body image scale & $20(13-20)$ & $20(14-20)$ & 0.40 \\
\hline Cosmetic scale & $20(7-24)$ & $18(12-24)$ & 0.14 \\
\hline \multicolumn{4}{|l|}{ Recipient } \\
\hline Acute rejection & $9(18)$ & $15(30)$ & 0.24 \\
\hline Ureteral complications & $6(12)$ & $10(20)$ & 0.41 \\
\hline Graft survival at one yearł & $48(100)$ & $48(98)$ & 1.00 \\
\hline Patient survival at one year & $48(96)$ & $49(98)$ & 1.00 \\
\hline
\end{tabular}

*Adjusted for time spent in hospital for non-medical reasons.

tMeasured on visual analogue scale from 0 (none) to 10 (severe).

tCensored for death.

Physical fatigue scores were significantly lower for donors in the laparoscopic group, indicating less physical fatigue (fig 2): difference during one year's follow-up $(-1.3,95 \%$ confidence interval -2.4 to $-0.1, \mathrm{P}=0.03$ ). Other dimensions of fatigue did not differ between the groups over time (see bmj.com).

\section{Discussion}

Laparoscopic donor nephrectomy results in faster recovery, less fatigue, and better quality of life of the donor compared with mini incision open donor nephrectomy but equal safety and graft function.
Table 3 Quality of life of living kidney donors after laparoscopic nephrectomy or mini incision open nephrectomy

\begin{tabular}{lcc} 
& $\begin{array}{c}\text { Estimated difference (95\% Cl) } \\
\text { (laparoscopic nephrectomy minus } \\
\text { open nephrectomy) }\end{array}$ & P value \\
\hline Dimension & $6.2(2.0$ to 10.3$)$ & \\
\hline SF-36: & $7.7(-2.1$ to 17.5$)$ & 0.004 \\
\hline Physical function & $4.1(-0.3$ to 8.5$)$ & 0.12 \\
\hline Role physical & $7.2(2.2$ to 12.1$)$ & 0.07 \\
\hline Bodily pain & $6.7(1.1$ to 12.2$)$ & 0.005 \\
\hline General health & $5.9(0.5$ to 11.4$)$ & 0.02 \\
\hline Vitality & $11.8(4.1$ to 19.5$)$ & 0.03 \\
\hline Social functioning & $5.6(1.8$ to 9.4$)$ & 0.003 \\
\hline Role emotional & & 0.005 \\
\hline Mental health & & \\
\hline Multidimensional fatigue & & \\
inventory: & $-0.7(-2.0$ to 0.6$)$ & 0.31 \\
\hline General fatigue & $-1.3(-2.4$ to -0.1$)$ & 0.16 \\
\hline Physical fatigue & $-0.8(-2.0$ to 0.3$)$ & 0.07 \\
\hline Reduced activities & $-1.0(-2.1$ to 0.1$)$ & 0.70 \\
\hline Reduced motivation & $-0.2(-1.7$ to 0.3$)$ & \\
\hline Mental fatigue &
\end{tabular}

Positive differences on SF-36 dimensions indicate better quality of life after laparoscopic donor nephrectomy. Negative differences on multidimensional fatigue inventory dimensions indicate less fatigue after laparoscopic donor nephrectomy.

Most studies have investigated perioperative complications and recovery shortly after nephrectomy using different techniques. Three randomised trials compared hand assisted laparoscopic donor nephrectomy with mini incision open donor nephrectomy without blinding. ${ }^{11-13}$ Mini incision open donor nephrectomy has been proposed as an acceptable alternative to laparoscopic surgery, ${ }^{14}$ particularly if complications are expected.

We did not exclude donors for laparoscopic nephrectomy because of factors such as high body mass index. Unlike traditional lumbotomy, the applied open approach used a small incision and preserved continuity of abdominal wall muscles
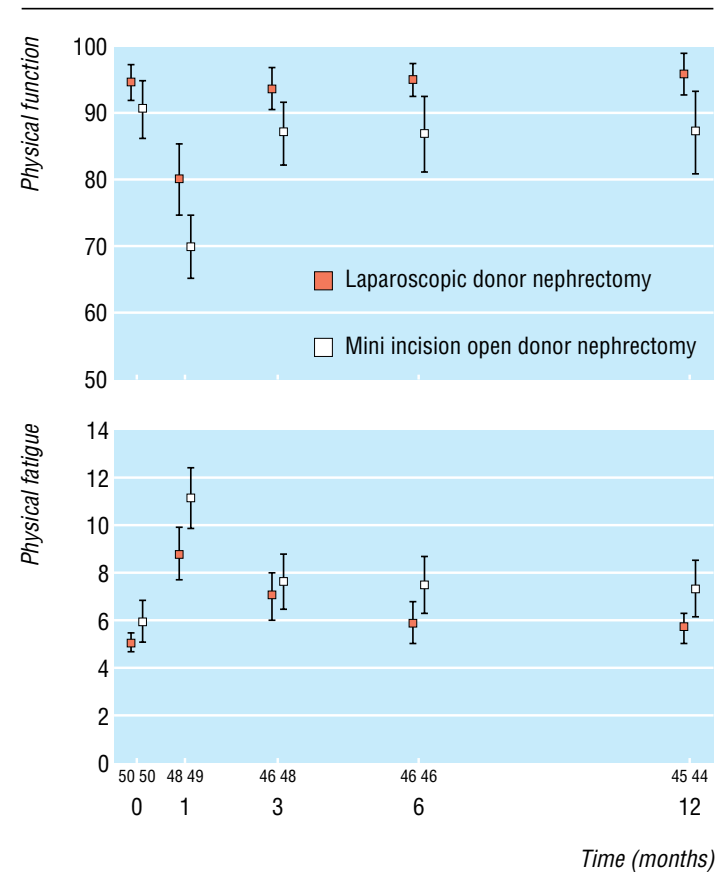

Fig 2 Physical function and physical fatigue (means with 95\% confidence intervals) during follow-up of living kidney donors after laparoscopic nephrectomy or mini incision open donor nephrectomy. Numbers refer to donors evaluated at each time point 
resulting in fewer complications, fast recovery, ${ }^{15}{ }^{16}$ and cosmetic outcomes equivalent to laparoscopic nephrectomy. Despite modification of the open technique, laparoscopic nephrectomy was superior for recovery and, more importantly, fatigue and quality of life during follow up. The use of blood stained wound dressings blinded donors and medical staff in the immediate postoperative phase. In previous reports on laparoscopic cholecystectomy compared with open cholecystectomy this strategy avoided bias caused by medical staff. ${ }^{18}$ Although bias could have been present after discharge, this is the best possible blinding. The difference in variables measured after the operation, such as pain scores and length of hospital stay, was significantly in favour of laparoscopic nephrectomy, despite blinding.

Restoring quality of life is of utmost importance after living kidney donation. Other retrospective studies showed an improved quality of life after laparoscopic surgery compared with conventional open surgery. ${ }^{19}{ }^{20}$ In our study laparoscopic surgery led to a better quality of life of donors. In studies of laparoscopic compared with open surgery for benign or malignant conditions, quality of life is at best considered a secondary outcome. Removal and permanent correction of the abnormality is the primary outcome and influences the feelings of patients postoperatively. Conversions from laparoscopic to open techniques often obscure the effect of the operation on quality of life. As donors are healthy individuals the benefits they achieve from laparoscopic surgery resemble the actual benefits for patients undergoing laparoscopic operations.

Although the benefits of laparoscopic nephrectomy were obvious in our study, extensive experience in laparoscopic surgery is necessary before implementation of a kidney donation programme using laparoscopic techniques. Complications, although rare, did occur in our study. Furthermore, the operation time was about an hour longer for laparoscopic nephrectomy. This was attributed to the time needed to set up for surgery and the inclusion of donors with more difficult anatomy. Alternatives closely related to laparoscopic nephrectomy need to be explored to tackle these issues. Retroperitoneoscopic donor nephrectomy may combine the advantage of a shorter operation time and a lower chance of complications from lesions of intraperitoneal organs. ${ }^{21}$ Laparoscopic donor nephrectomy may be advocated for donation programmes using living kidney donors.

We thank J G van Duuren-van Pelt, data manager, and I P J Alwayn, surgeon, for their contributions to this study.

Contributors: WW, BMEH, GJvdW, EJH, IRAMMzB, HJB, JAvdV, and JNMI contributed to the design and initial planning of this study. BMEH, BCK, $\mathrm{HJB}$, and JNMIJ attended all operations and controlled the carrying out of the surgical technique. NFMK, MYL, EJH, and DP collected the donors' data. WW and IMD collected the recipients' data. WCJH was the trial statistician. NFMK, EMMA, and GJvdW were responsible for collecting, analysing, interpreting, and writing up the quality of life data. IRAMMzB supervised and controlled the anaesthesiology protocol. NFMK, WW, JNMI,

\section{What is already known on this topic}

Both laparoscopic donor nephrectomy and minimally invasive open donor nephrectomy provide better outcomes than conventional open donor nephrectomy

\section{What this study adds}

Compared with mini incision open donor nephrectomy, laparoscopic donor nephrectomy was associated with faster recovery, less fatigue, and better quality of life of the donor but equal safety and graft function and EMMA coordinated the writing and drafting of the article. JNMI is guarantor.

Funding: This study was supported by unrestricted grants from the Society of American Gastrointestinal Endoscopic Surgeons and the Dutch Kidney Foundation.

Competing interest: None declared.

Ethical approval: This study was approved by the medical ethics committees of the university medical centres at Rotterdam and Nijmegen.

1 Ingelfinger JR. Risks and benefits to the living donor. N Engl J Med 2005;353:447-9.

2 Ratner LE, Ciseck LJ, Moore RG, Cigarroa FG, Kaufman HS, Kavoussi LR. Laparoscopic live donor nephrectomy. Transplantation 1995;60:1047-9.

3 Srivastava A, Tripathi DM, Zaman W, Kumar A. Subcostal versus transcostal mini donor nephrectomy: is rib resection responsible for pain related donor morbidity. J Urol 2003; $170: 738-40$.

4 Yang SL, Harkaway R, Badosa F, Ginsberg P, Greenstein MA. Minimal incision living donor nephrectomy: improvement in patient outcome. Urology 2002;59:673-7.

5 Kok NF, Alwayn IP, Lind MY, Tran KT, Weimar W, Ijzermans JN. Donor nephrectomy: mini-incision muscle-splitting open approach versus laparoscopy. Transplantation 2006;81:881-7.

6 Lind MY, Hazebroek EJ, Hop WC, Weimar W, Jaap Bonjer H, IJzermans JN. Right-sided laparoscopic live-donor nephrectomy: is reluctance still justified? Transplantation 2002;74:1045-8

7 Dunker MS, Bemelman WA, Slors JF, van Duijvendijk P, Gouma DJ. Functional outcome, quality of life, body image, and cosmesis in patients after laparoscopicassisted and conventional restorative proctocolectomy: a comparative study. Dis Colon Rectum 2001;44:1800-7.

8 Ware JE, Snow KK, Kosinski M, Gandek B. SF-36 health survey. Manual and interpretation guide. Boston, MA: Health Institute, New England Medical Center, 1993.

9 Smets EM, Garssen B, Cull A, de Haes JC. Application of the multidimensional fatigue inventory (MFI-20) in cancer patients receiving radiotherapy. $\mathrm{Br} J$ Cancer 1996;73:241-5.

10 De Klerk M, Keizer KM, Claas FH, Witvliet M, Haase-Kromwijk BJ, Weimar W. The Dutch national living donor kidney exchange program. Am J Transplant 2005;5:2302-5.

11 Wolf JS Jr, Merion RM, Leichtman AB, Campbell DA Jr, Magee JC, Punch JD, et al. Randomized controlled trial of hand-assisted laparoscopic versus open surgical live donor nephrectomy. Transplantation 2001;72:284-90.

12 Simforoosh N, Basiri A, Tabibi A, Shakhssalim N, Hosseini Moghaddam SM. Comparison of laparoscopic and open donor nephrectomy: a randomized controlled trial. $\mathrm{BrJ}$ Urolog Int 2005;95:851-5.

13 Oyen O, Andersen M, Mathisen L, Kvarstein G, Edwin B, Line PD, et al. Laparoscopic versus open living-donor nephrectomy: experiences from a prospective, randomized, single-center study focusing on donor safety. Transplantation 2005;79:1236-40.

14 Lewis GR, Brook NR, Waller JR, Bains JC, Veitch PS, Nicholson ML. A comparison of traditional open, minimal-incision donor nephrectomy and laparoscopic donor traditional open, minimal-incision don
nephrectomy. Transpl Int 2004;17:589-95.

15 Berends FJ, den Hoed PT, Bonjer HJ, Kazemier G, van Riemsdijk I, Weimar W, et al. Terends FJ, den Hoed PT, Bonjer HJ, Kazemier G, van Riemsdijk I, Weimar W, et al.
Tensiderations and pitfalls in laparoscopic live donornephrectomy. Surg Endosc 2002;16:893-8.

16 Lind MY, Liem YS, Bemelman WA, Dooper PM, Hop WC, Weimar W, et al. Live donor nephrectomy and return to work: does the operative technique matter? Surg Endosc 2003;17:591-5.

17 Majeed AW, Troy G, Nicholl JP, Smythe A, Reed MW, Stoddard CJ, et al. Randomised, prospective, single-blind comparison of laparoscopic versus small-incision cholecystectomy. Lancet 1996;347:989-94.

18 Johansson M, Thune A, Nelvin L, Stiernstam M, Westman B, Lundell L. Randomized clinical trial of open versus laparoscopic cholecystectomy in the treatment of acute clinical trial of open versus laparos
cholecystitis. Br J Surg 2005;92:44-9.

19 Perry KT, Freedland SJ, Hu JC, Phelan MW, Kristo B, Gritsch AH, et al. Quality of life, pain and return to normal activities following laparoscopic donor nephrectomy versus open mini-incision donor nephrectomy.J Urol 2003;169:2018-21.

20 Buell JF, Lee L, Martin JE, Dake NA, Cavanaugh TM, Hanaway MJ, et al. Laparoscopic donor nephrectomy vs open live donor nephrectomy: a quality of life and functional study. Clin Transplant 2005;19:102-9.

21 Wadstrom J. Hand-assisted retroperitoneoscopic live donor nephrectomy: experience from the first 75 consecutive cases. Transplantation 2005;80:1060-6.

(Accepted 25 May 2006)

doi $10.1136 / \mathrm{bmj} .38886 .618947 .7 \mathrm{C}$

Department of Surgery, Erasmus MC, PO Box 2040, 3000 CA Rotterdam, Netherlands

Niels F M Kok research fellow

May Y Lind surgical resident

Eric J Hazebroek surgical resident

Hendrik J Bonjer professor

Jan N M IJzermans professor of transplantation surgery

Department of Surgery, Radboud University Medical Centre, Nijmegen, Netherlands

Birgitta M E Hansson consultant

Jordanus A van der Vliet consultant

Department of Nephrology, Radboud University Medical Centre

Desiree Pilzecker research fellow

Ine M Dooper consultant

Department of Anaesthesiology, Erasmus MC 


\section{Research}

Ingrid R A M Mertens zur Borg consultant

Department of Urology, Radboud University Medical Centre Ben C Knipscheer consultant

Department of Nephrology, Erasmus MC

Willem Weimar professor of transplantation

Department of Epidemiology and Biostatistics, Erasmus MC
Wim C J Hop statistician

Department of Medical Technology Assessment, Radboud University Medical Centre

Eddy M M Adang deputy head

Gert Jan van der Wilt head of department

Correspondence to: J N M IJzermans j.ijzermans@erasmusmc.nl 